University of Nebraska - Lincoln

DigitalCommons@University of Nebraska - Lincoln

\title{
IDENTIFYING AND EVALUATING A SUITABLE INDEX FOR AGRICULTURAL DROUGHT MONITORING IN THE TEXAS HIGH PLAINS
}

Jerry E. Moorhead

Department of Agriculture, West Texas A\&M University, jed.moorhead@ars.usda.gov

Prasanna H. Gowda

prasanna.gowda@ars.usda.gov

Vijay P. Singh

Conservation \& Production Research Laboratory, USDA-ARS

Dana O. Porter

Texas A\&M University

Thomas H. Marek

Department of Biological and Agricultural Engineering, Texas A\&M AgriLife Research and Extension Service

Follow this and additional works at: https://digitalcommons.unl.edu/usdaarsfacpub See next page for additional authors

Part of the Environmental Indicators and Impact Assessment Commons, and the Environmental

Monitoring Commons

Moorhead, Jerry E.; Gowda, Prasanna H.; Singh, Vijay P.; Porter, Dana O.; Marek, Thomas H.; Howell, Terry A.; and Stewart, B A., "IDENTIFYING AND EVALUATING A SUITABLE INDEX FOR AGRICULTURAL DROUGHT MONITORING IN THE TEXAS HIGH PLAINS" (2015). Publications from USDA-ARS / UNL Faculty. 1506.

https://digitalcommons.unl.edu/usdaarsfacpub/1506

This Article is brought to you for free and open access by the U.S. Department of Agriculture: Agricultural Research Service, Lincoln, Nebraska at DigitalCommons@University of Nebraska - Lincoln. It has been accepted for inclusion in Publications from USDA-ARS / UNL Faculty by an authorized administrator of DigitalCommons@University of Nebraska - Lincoln. 


\section{Authors}

Jerry E. Moorhead, Prasanna H. Gowda, Vijay P. Singh, Dana O. Porter, Thomas H. Marek, Terry A. Howell, and B A. Stewart 


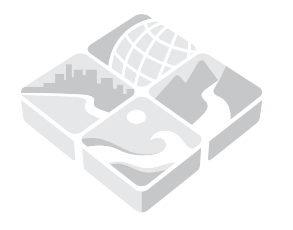

\title{
IDENTIFYING AND EVALUATING A SUITABLE INDEX FOR AGRICULTURAL DROUGHT MONITORING IN THE TEXAS HIGH PLAINS ${ }^{1}$
}

\author{
Jerry E. Moorhead, Prasanna H. Gowda, Vijay P. Singh, Dana O. Porter, \\ Thomas H. Marek, Terry A. Howell, and B.A. Stewart ${ }^{2}$
}

\begin{abstract}
Drought is a complex and highly destructive natural phenomenon that affects portions of the United States almost every year, and severe water deficiencies can often become catastrophic for agricultural production. Evapotranspiration (ET) by crops is an important component in the agricultural water budget; thus, it is advantageous to include ET in agricultural drought monitoring. The main objectives of this study were to (1) conduct a literature review of drought indices with a focus to identify a simple but simultaneously adequate drought index for monitoring agricultural drought in a semiarid region and (2) using the identified drought index method, develop and evaluate time series of that drought index for the Texas High Plains. Based on the literature review, the Standardized Precipitation-Evapotranspiration Index (SPEI) was found to satisfy identified constraints for assessing agricultural drought. However, the SPEI was revised by replacing reference ET with potential crop ET to better represent actual water demand. Data from the Texas High Plains Evapotranspiration network was used to calculate SPEIs for the major irrigated crops. Trends and magnitudes of cropspecific, time-series SPEIs followed crop water demand patterns for summer crops. Such an observation suggests that a modified SPEI is an appropriate index to monitor agricultural drought for summer crops, but it was found to not account for soil water stored during the summer fallow period for winter wheat.
\end{abstract}

(KEY TERMS: evapotranspiration; Standardized Precipitation Index; Standardized Precipitation-Evapotranspiration Index; semiarid regions.)

Moorhead, Jerry E., Prasanna H. Gowda, Vijay P. Singh, Dana O. Porter, Thomas H. Marek, Terry A. Howell, and B.A. Stewart, 2015. Identifying and Evaluating a Suitable Index for Agricultural Drought Monitoring in the Texas High Plains. Journal of the American Water Resources Association (JAWRA) 1-14. DOI: 10.1111/jawr. 12275

\section{INTRODUCTION}

Drought is a complex natural phenomenon that can cause devastating losses across large regions. In agricultural regions, losses can come in the form of reduced crop yield and reduced forage and even crop failure or livestock death. Crop losses can be somewhat mitigated with timely irrigation. When drought conditions occur, precipitation is typically scarce and

\footnotetext{
${ }^{1}$ Paper No. JAWRA-14-0113-P of the Journal of the American Water Resources Association (JAWRA). Received May 8, 2014; accepted October 29, 2014. () 2015 American Water Resources Association. Discussions are open until six months from print publication.

${ }^{2}$ Biological Science Technician (Moorhead), Research Agricultural Engineer (Gowda), and Retired Laboratory Director and Research Leader (Agricultural Engineer) (Howell), Conservation \& Production Research Laboratory, USDA-ARS, PO Drawer 10, Bushland, Texas 79012; Distinguished Chair and Distinguished Professor (Singh), Department of Biological and Agricultural Engineering, Texas A\&M University, College Station, Texas 77843; Associate Professor and Extension Agricultural Engineering Specialist (Porter), Department of Biological and Agricultural Engineering, Texas A\&M AgriLife Research and Extension Service, Lubbock, Texas 79403; Research Agricultural Engineer (Marek), Department of Biological and Agricultural Engineering, Texas A\&M AgriLife Research, Amarillo, Texas 79106; Director, Dryland Agriculture Institute and Distinguished Professor (Stewart), Department of Agriculture, West Texas A\&M University, Canyon, Texas 79016 (E-Mail/Moorhead: jed.moorhead@ars.usda.gov).
} 
more water evaporates to the environment, which in turn demands relatively more irrigation to meet the crop water needs, and the amount of irrigation applied is increased (if possible) to sustain production. Increased irrigation application, however, places greater demand on available water resources that are likely to be subject to additional demands from the drought conditions while simultaneously increased irrigation costs reduce net profits.

Agricultural drought can be best monitored using a drought index that simultaneously uses both precipitation and evapotranspiration (ET), two major components of the water budget. ET represents the loss of water from the soil through soil evaporation and plant transpiration, whereas precipitation represents addition of water to the soil. The difference between the two components represents irrigation demand in arid and semiarid regions where inadequate precipitation is expected during the growing season and is supplemented by irrigation. Therefore, these two components are essential parts of monitoring agricultural drought conditions and for determining irrigation requirements. The main objectives of this study were to (1) conduct a detailed review of drought indices available in the literature to determine a suitable drought index for monitoring agricultural drought and (2) calculate and evaluate time series of the selected drought index for the Texas High Plains.

\section{LITERATURE REVIEW}

Numerous drought indices have been developed over time and are variously applied throughout the literature (Heim, 2002; Mishra and Singh, 2010; Sivakumar et al., 2011). Munger (1916) reported that the intensity of droughts were more harmful than their length. Therefore, Munger used the number of consecutive days where 24 -h rainfall was less than $1.27 \mathrm{~mm}$ (0.05 in.) to develop a drought index for studying fire hazard in the Pacific Northwest. Munger (1916) then developed a graphical technique to represent the intensity of the drought using the area of a right triangle whose height and base were proportional to the duration of drought. The equation for Munger's index was the square of the length of the drought in days divided by two.

Kincer (1919) prepared a series of maps and charts showing seasonal distribution of precipitation and distribution of the average annual number of days with precipitation of various intensities. Kincer's work was the first work of this type that had been performed. Kincer used a drought definition of 30 or more consecutive days with less than $6.35 \mathrm{~mm}$ (0.25 in.) of precipitation in $24 \mathrm{~h}$. Marcovitch (1930) developed an index based on the climatic requirements for the bean beetle in the eastern United States (U.S.). This index incorporated both temperature and precipitation using the total number of two or more consecutive days above $32^{\circ} \mathrm{C}\left(90^{\circ} \mathrm{F}\right)$ and the total summer rainfall for the same period. Blumenstock (1942) used probability theory to conduct a climate study on drought frequencies, and Blumenstock used the length of drought in days where a drought was terminated by at least $2.54 \mathrm{~mm}$ (0.10 in.) of precipitation in $48 \mathrm{~h}$ or less. McGuire and Palmer (1957) developed an index that used potential ET (PET) termed as the Moisture Adequacy Index (MAI). This index compared the water need to the rainfall and stored soil water for a given location. The MAI is expressed as a percentage of the actual water supply compared to the water need.

After extreme droughts occurred over very large regions of the U.S. during the 1930s and again in the 1950 s, more drought research was conducted and new drought indices were developed in an attempt to better quantify and study drought. Both instances affected much of the Texas High Plains. Interest in drought research has further increased because of the ongoing extreme drought in the region (Baumhardt et al., 2014). A list of common drought indices that are found in the literature is presented in Table 1.

\section{Palmer Drought Severity Index}

The Palmer Drought Severity Index (PDSI) (Palmer, 1965) was derived to provide a methodology for calculating an index for evaluating the meteorological anomaly characterized by a prolonged and abnormal water deficiency for a variety of time scales. Palmer's objective was to use a specific definition of drought and create a measurement technique that would allow for comparison of drought events. Palmer noticed that a variety of drought definitions existed, and to define what drought means precisely for all invested stakeholders would be extremely difficult. Palmer concluded that all drought indices dealt with variations in water deficiency and generalized the drought definition to "a prolonged and abnormal moisture deficiency." Use of a generalized drought definition allowed Palmer to derive an index that could be used with any definition of drought.

Palmer (1965) attempted to develop a procedure to compute the amount of precipitation that would be considered climatically normal for a given area. One problem with using derived water deficiencies and excesses for a number of time periods, however, is 
Identifying and Evaluating a Suitable Index for Agricultural Drought Monitoring in the Texas High Plains

TABLE 1. Commonly Used Drought Indices.

\begin{tabular}{|c|c|c|}
\hline Index & Classification & Input Parameters \\
\hline Palmer Drought Severity Index (PDSI — Palmer, 1965) & Meteorological & $\begin{array}{l}\text { Soil characteristics, } \\
\text { reference ET, precipitation }\end{array}$ \\
\hline Crop Moisture Index (CMI — Palmer, 1968) & Agricultural & Same as PDSI \\
\hline Surface Water Supply Index (SWSI — Shafer and Dezman, 1982) & Hydrological & Soil water, stream flow \\
\hline Palmer Hydrological Drought Index (PHDI — Karl, 1986) & Hydrological & Same as PDSI \\
\hline Standardized Precipitation Index (SPI — McKee et al., 1993) & Meteorological & Precipitation \\
\hline Reclamation Drought Index (Hayes, 2006) & Hydrological & Temperature, precipitation, stream flow \\
\hline Vegetation Condition Index (VCI — Kogan, 1995) & Agricultural & Satellite images \\
\hline U.S. Drought Monitor (NDMC, 2013) & Meteorological & $\begin{array}{l}\text { Precipitation, various drought indices, } \\
\text { groundwater level, reservoir storage }\end{array}$ \\
\hline Standardized Vegetation Index (SVI — Peters et al., 2002) & Agricultural & Remote sensing data \\
\hline Reconnaissance Drought Index (RDI — Tsakiris and Vangelis, 2005) & Agricultural & Actual ET, PET \\
\hline Soil Moisture Deficit Index (SMDI — Narasimhan and Srinivasan, 2005) & Agricultural & Soil water \\
\hline $\begin{array}{l}\text { Evapotranspiration Deficit Index (ETDI - Narasimhan } \\
\text { and Srinivasan, 2005) }\end{array}$ & Agricultural & Actual ET, PET \\
\hline $\begin{array}{l}\text { Standardized Precipitation-Evapotranspiration Index } \\
\text { (SPEI - Vicente-Serrano et al., 2010) }\end{array}$ & Meteorological & Precipitation, reference ET \\
\hline Accumulated Drought Index (ADI - CIIAGRO, 2012) & Agricultural & Precipitation, reference ET \\
\hline Relative Water Deficit (RWD - Sivakumar et al., 2011) & Agricultural & Actual ET, PET \\
\hline
\end{tabular}

Note: PET, potential evapotranspiration; ET, evapotranspiration.

that it does not take drought duration into account. In addition, departures from normal vary from one location to another. To overcome these issues, a weighting scheme was developed to transform the departures in accordance with their significance to the climate of the location being considered. In the end, all these needed to be combined into an index of abnormality for an extended duration of drought, and systematic procedures derived for delineating the abnormal periods. As a result, Palmer (1965) computed water excess or deficiency using a water balance or hydrologic accounting approach. Such an approach considers water inputs and losses to produce a current state of water at site or regional scales. The primary water loss in Palmer's approach is PET. In Palmer's process, PET is calculated using Thornthwaite's formula (Thornthwaite, 1948). The calculation methodology for the PDSI is available in Palmer (1965).

The PDSI provides the capability for comparisons across regions and time scales; however, limitations to PDSI exist. In the hydrological accounting procedure, Palmer assumes that ET takes place at the potential rate when precipitation is greater than PET. Because of the nature of the occurrence of precipitation, this may not be true for all of the time periods used (Alley, 1984). In some instances, substantial precipitation may fall in the beginning or end of the time period. This inherently leads to either over- or underestimation of ET.

Alley (1984) noted that in Palmer's two-layer soil profile, the water capacity of the surface layer of the soil is $25 \mathrm{~mm}$, which can physically and numerically go from full to empty in a single month. The $25 \mathrm{~mm}$ of water capacity in the surface layer is minor compared to the underlying layer, which results in water balance methods being insensitive to the inclusion of the surface layer. Furthermore, the runoff estimate in Palmer's method can be a source of deficiency in the computations. Palmer uses a "threshold-type" model in assuming runoff which assumes that runoff does not occur until the available water capacity of both layers of the soil is filled (Alley, 1984) — this may not always be a valid assumption.

Karl (1986) studied the sensitivity of PDSI to its assumptions and parameters. Because of the complexity of the water budget system, relatively few studies have investigated this aspect. Karl observed that the $Z$-index, calculated in the PDSI procedure as a single point indicator of drought or wetness, was likely to be more adequate for agricultural water shortages than would the PDSI. The observation was attributed to the fact that the $Z$-index is more responsive to short-term soil water changes than PDSI. The PDSI is more suited as a meteorological index with a longer time scale. The $Z$-index is calculated before duration is taken into account, which allows for a shorter time scale. The $Z$-index still behaves as a meteorological drought index where the first month the weather goes from dry to normal, or vice versa, the drought or wet spell ends even though the soil water may still be above or below their normal levels.

\section{Crop Moisture Index}

The Crop Moisture Index (CMI) was developed by Palmer (1968) to provide a drought monitoring tool 
for agricultural regions. Palmer noted the difficulty in using a meteorological approach to monitor agricultural drought because of variations in soils, crop types, and precipitation amounts. However, Palmer (1968) did see the need for a broad scale general drought monitoring method, such as monitoring the crop water situation in a soybean producing region. Using the output from the PDSI, Palmer combined the weekly ET deficit into an index of the ET anomaly, which is a measure of cumulative agricultural drought. To account for wet weather, where excessive water can damage crops, Palmer combined the recharge and runoff components of the PDSI into a wetness index. The ET index is usually negative while the wetness index is positive. The final CMI is the sum of these two values. The CMI is near zero under normal conditions, positive for wet conditions, and negative for dry conditions. The CMI provides a shorter time scale than the PDSI, which is more suited for agricultural drought. The CMI has the same limitations and complexity as the PDSI.

\section{Surface Water Supply Index}

The Surface Water Supply Index (SWSI) was developed by Shafer and Dezman (1982) to improve limitations from the PDSI. The SWSI is an indicator of hydrological drought and is based on nonexceedance probabilities of reservoir storage, stream flow, snowpack, and precipitation (Mishra and Singh, 2010). The SWSI is designed to monitor surface water supply sources, which limits its usefulness for agricultural drought monitoring.

\section{Palmer Hydrological Drought Index}

The Palmer Hydrological Drought Index (PHDI) refers to the PDSI when calculated using real time data (Karl, 1986). The main difference between the PDSI and the PHDI is the treatment of the beginning and ending times of droughts or wet periods. The beginning and ending of a drought is determined by the ratio of moisture received to the moisture required to definitively end a drought and is expressed as a percentage (termed $\mathrm{P}_{\mathrm{e}}$ ). For the PDSI, a drought is considered to have ended when $\mathrm{P}_{\mathrm{e}}$ becomes greater than zero, and continues to be greater than zero until reaching $100 \%$. In real time, it cannot be known if a period of time with $\mathrm{P}_{\mathrm{e}}$ greater than zero demarks a temporary interruption of the current drought (Karl, 1986). For the PHDI, the drought is not considered to have ended until $\mathrm{P}_{\mathrm{e}}$ reaches $100 \%$. Thus, the PDSI and PHDI are different only when $\mathrm{P}_{\mathrm{e}}$ is greater than zero and less than $100 \%$.

\section{Standardized Precipitation Index}

The Standardized Precipitation Index (SPI) was developed by McKee et al. (1993) in response to deficiencies seen in the PDSI. They described the need for a probability based drought monitoring method and noted that the use of the PDSI is limited, in part because of its undefined yet inherently built-in time scale. Those authors also pointed out the differences in the various drought definitions, as outlined by Dracup et al. (1980) and Wilhite and Glantz (1985) and the effect these differences had on drought monitoring. It was noted that all drought definitions classify drought as a condition of insufficient water because of a lack of precipitation. To provide an index and drought definition, the SPI was created. The SPI defines drought based on standardized precipitation. It is simple to calculate and can be used for any single parameter and time scale desired. To calculate the SPI, the precipitation data must first be fitted to a probability distribution which best fits or adequately mimics the data. For example, the normal distribution is not always appropriate. The step of distribution choice and parameter estimation is often overlooked by some investigators (Guttman, 1999). After a distribution is fit to the data, the SPI is calculated by taking the difference of precipitation from the mean for a time period divided by the standard deviation.

The SPI requires only one input parameter so it can be used for precipitation as well as snowpack, stream flow, reservoir storage, soil water, or groundwater. This feature allows it to be used for any drought definition. In addition, the SPIs that are based on different parameters can be compared and contrasted. Mishra and Singh (2010) pointed out that the greatest strength of the SPI is its ability to be used on multiple time scales. This ability makes the SPI useful in monitoring drought according to multiple definitions. A disadvantage of the SPI is that using precipitation (or any single parameter) alone does not describe all factors that influence drought. For example, a period with average precipitation should indicate that there are no drought conditions present, even though the evaporative demands could be well above average, creating a water shortage.

Also, the SPI is sensitive to the length of the precipitation record for the area of interest where the SPI values may differ when computed from different lengths of record. The SPI values can exhibit similar results when different precipitation records have similar gamma distributions (Mishra and Singh, 2010). Because of the nature of the variability of precipitation, it can be difficult to fit the precipitation data to conventional probability distributions. Several different distributions, such as normal, gamma, and 
Pearson III, are widely used with each distribution resulting in differing nuances to SPI interpretation.

\section{Reclamation Drought Index}

The Reclamation Drought Index was developed in response to the Reclamation States Drought Assistance Act of 1988, which allowed states to seek assistance from the Bureau of Reclamation to financially mitigate for the effects of drought. The Reclamation Drought Index is similar to the SWSI in that it is calculated at a river basin level. The Reclamation Drought Index uses precipitation, snowpack, stream flow, and reservoir levels (Hayes, 2006). The large spatial scale used in the Reclamation Drought Index limits its application for agricultural drought because of the variations in agricultural practices over large regions.

\section{Vegetation Condition Index}

The Vegetation Condition Index (VCI) was developed by Kogan (1995). It uses the Normalized Difference Vegetation Index (NDVI) obtained from satellite data. The VCI is a normalization of the NDVI that allows for relative assessments of changes in the NDVI (Quiring, 2009). One issue with NDVI-based drought monitoring is that whereas NDVI does provide an indication of plant health, it is difficult to distinguish between crop types, and it is difficult to distinguish whether plant stress is attributable to drought alone or other stressors (disease, pests, nutrients).

\section{U.S. Drought Monitor}

The U.S. Drought Monitor combines many drought indices into a single graphical representation that provides a summary of drought conditions for the U.S. The U.S. Drought Monitor also uses input from over 270 multiagency experts across the U.S. (NDMC, 2013). This drought map is designed to be simultaneously informative to the general public as well as the scientific community. Because the U.S. Drought Monitor was designed to be a graphical portrayal of drought conditions, its usefulness as a real-time agricultural drought monitoring tool is limited.

\section{Standardized Vegetation Index}

The Standardized Vegetation Index (SVI), developed by Peters et al. (2002), uses a standardization procedure on NDVI that is obtained from satellite data. The SVI is similar to the VCI and has similar limitations for agricultural drought monitoring.

It is observed by the authors that the drought indices identified herein do well for monitoring meteorological drought, but can present challenges in monitoring agricultural drought. ET and soil water storage are the two major components in the agricultural water budget. ET represents the basic water need for a crop, thus is very beneficial in the calculation of an agricultural drought index, and soil moisture storage indicates the basic water availability. Reference ET can be estimated for most regions in the U.S. as weather data are readily available. However, soil water values and soil characteristics can be difficult to obtain. Without accurate data, indices, including soil moisture, may be difficult to compute on some scales. Because of this, a drought index is desired that includes ET, but does not utilize soil water or soil characteristics.

Five drought indices that meet these constraints are: SPEI, ETDI, RDI, ADI, and RWD. These indices either use the difference in precipitation and PET of a reference crop or the ratio of actual ET to PET to quantify water availability to plants. Precipitation is considered as addition of water whereas ET is the loss of water. The difference will illustrate the change in stored soil water. PET is the maximum rate at which water will be utilized by the plant. When a water stress is imposed, the plants do not take up water at the potential rate; therefore, the ratio of actual ET to PET will indicate water stress conditions. However, the term PET refers to the maximum ET rate for a specific crop, which is difficult to calculate directly. Thus, the PET for a reference crop of known height, under well-watered conditions, is often what is calculated. This provides the PET for a reference crop or reference $\mathrm{ET}\left(\mathrm{ET}_{\mathrm{o}}\right)$. For the indices that use the ratio of actual ET to PET, this ratio is only suitable if the actual ET and PET are for the same crop.

\section{Evapotranspiration Deficit Index and Soil Moisture Deficit Index}

The Evapotranspiration Deficit Index (ETDI) and Soil Moisture Deficit Index (SMDI) were developed by Narasimhan and Srinivasan (2005) in an attempt to provide a better index for monitoring agricultural drought. Because of the SMDI using soil water as input and the difficulty in acquiring soil water data, the SMDI is excluded from further discussion. More information on the SMDI can be found in Narasimhan and Srinivasan (2005). After noticing the deficiencies in PDSI and SPI, Narasimhan and Srinivasan sought to develop an agricultural drought index that could be produced at a much finer resolution than that of PDSI or SPI. Because of the variability of precipitation and 
soil characteristics, finer resolution is preferred for drought indices that utilize these factors. The first step in calculating the ETDI is to calculate the weekly water stress ratio (WS):

$$
\mathrm{WS}=\frac{\mathrm{PET}-\mathrm{AET}}{\mathrm{PET}}
$$

where AET is the actual ET. The WS value has a range from 0 to 1 with 0 indicating actual ET at the potential rate and 1 indicating no actual ET. After calculating the WS, the maximum, minimum, and median water stress are used to calculate the weekly water stress anomaly (WSA) as outlined in Narasimhan and Srinivasan (2005). The WSA values will range from -100 to +100 with negative values indicating dry conditions and positive values indicating wet conditions. Seasonality is inherently removed from the WSA; therefore, it can be compared across seasons. A detailed explanation of the procedure can be found in Narasimhan and Srinivasan (2005).

When water is limited, plants cannot transpire at the potential rate. Because of this fact, the ratio of actual ET to PET closely reflects the stress on the plant. This ratio can be more indicative of agricultural drought than the indices that use precipitation. Even though a shortage in precipitation is likely to cause water stress on a plant, it is not a direct indication. The limitation to this drought index is that actual crop ET data are difficult to obtain. In addition, the PET must be for the same crop as the actual ET. Reference ET is often used as the PET; however, reference ET is only valid for the reference crop. Different crops will have different relationships to reference ET; therefore, reference ET alone would be insufficient. It is possible to estimate potential crop ET using reference ET and crop coefficients. This estimate would provide an ET value based on well-watered conditions. To use an appropriate ET ratio, it would be more accurate to utilize actual ET, obtained from tools such as lysimeters or thermal remote sensing techniques (Gowda et al., 2008), and estimated crop PET, obtained from reference ET and crop coefficients. Doing this would provide a measure of the stress under given conditions compared to estimated, nonstressed conditions, but does include complicated data needs.

\section{Reconnaissance Drought Index}

The Reconnaissance Drought Index (RDI) was developed by Tsakiris and Vangelis (2005) to develop a drought index that accounts for ET. They focused only on the natural processes that affect drought, such as precipitation, $\mathrm{ET}_{\mathrm{o}}$, and soil and vegetation cover characteristics. The ratio of precipitation to $\mathrm{ET}_{\mathrm{o}}$ has been used globally for some time with the aridity index developed by the United Nations Environmental Program (UNEP, 1992). The aridity index is the long-term mean of annual mean precipitation divided by the annual mean $\mathrm{ET}_{\mathrm{o}}$ and is defined as

$$
a_{k}=\frac{\sum_{j=1}^{j=k} P_{j}}{\sum_{j=1}^{j=k} \mathrm{ET}_{\mathrm{o}_{j}}}
$$

The aridity index indicates that both precipitation and PET are needed to measure dryness (Tsakiris and Vangelis, 2005). Although the aridity index was intended to categorize regional climates, the parameters could be used to assess drought. The RDI uses the ratio of cumulative precipitation and cumulative $\mathrm{ET}_{\mathrm{o}}$ for a given period. This ratio can then be standardized or normalized, as outlined in Tsakiris and Vangelis (2005), who note that drought cannot be monitored using only water inputs (precipitation). Using the output (ET) provides a more complete assessment of the status of water.

The RDI can also be calculated at any time scale, which adds versatility. In addition, it allows for comparison to other drought indices at various time scales. Although ET can be difficult to calculate, there are simpler methods that require minimal data inputs. With a simplistic ET calculation method, the RDI can be calculated without requiring complex datasets. Conversely, whereas precipitation and ET are important factors to consider in drought assessment, the ratio of precipitation to ET is not a very satisfactory relationship between the two parameters. Being that precipitation is a water input and ET is a water output, it is more logical to use the difference rather than the ratio. Also, even though there are simplistic methods available for calculating ET, the methods that require more data inputs are found to produce a more accurate ET estimate. For example, the ASCE-EWRI Standardized Reference ET Equation (Allen et al., 2005) is widely used throughout the U.S. and around the world and it is generally considered more accurate than simpler methods that are based on fewer data parameters.

\section{Standardized Precipitation Evapotranspiration Index}

The Standardized Precipitation Evapotranspiration Index (SPEI) was developed by Vicente-Serrano et al. (2010) with the intention of defining a drought index that would be sensitive to climate change. Vicente-Serrano et al. (2010) noted that the main factor influencing drought is precipitation; although other factors such as air temperature, ET, wind speed, and soil water holding capacity can also influence drought. The SPEI procedure is similar to that for SPI, but rather 
than using only precipitation, it uses the difference between precipitation and $\mathrm{ET}_{\mathrm{o}}$. In order to calculate the SPEI, $\mathrm{ET}_{\mathrm{o}}$ must first be estimated. Vicente-Serrano et al. (2010) used the Thornthwaite (1948) method but noted that other methods are available and acceptable. To calculate the SPEI, the difference $\left(D_{i}\right)$ between the precipitation and $\mathrm{ET}_{\mathrm{o}}$ is calculated by

$$
D_{i}=P_{i}-\mathrm{ET}_{\mathrm{o}_{i}}
$$

The $D_{i}$ values are then standardized which allows for comparison for different regions and time scales. Vicente-Serrano et al. (2010) provided equations for aggregating the $D_{i}$ values for computing the SPEI at longer time scales. To standardize the $D_{i}$ values, a three-parameter log-logistic distribution is used. The three-parameter log-logistic distribution was selected over a two-parameter log-logistic distribution to allow a range of values that can include negative numbers. First, the probability-weighted moments (PWMs), or equivalently the L-moments, are calculated to estimate the values for $\alpha, \beta$, and $\gamma$ parameters of the log-logistic distribution and thus fit the distribution to the data. The data are then standardized using an equation provided in Vicente-Serrano et al. (2010).

Similar to the SPI, the SPEI can be used across different drought definitions as it can be calculated at multiple time scales. In addition, because SPEI uses $\mathrm{ET}_{\mathrm{o}}$, it will inherently account for changes in wind speed, temperature, and other parameters that affect drought. One issue, however, is that using $\mathrm{ET}_{\mathrm{o}}$ in the calculation can be misleading in characterizing agricultural drought as now explained. In agriculture, $\mathrm{ET}_{\mathrm{o}}$ is usually higher than PET of most crops and PET of crops is zero during nongrowing season while $\mathrm{ET}_{\mathrm{o}}$ may not be zero. Moreover, the PET of a particular crop also depends on the crop stages whereas $\mathrm{ET}_{\text {o }}$ is calculated for standard crop conditions. Therefore, the use of $\mathrm{ET}_{\mathrm{o}}$ may not adequately express the water demands of a diversified crop environment.

\section{Accumulated Drought Index}

The Accumulated Drought Index (ADI) was developed by the Integrated Center of Agrometeorological Information in Brazil (CIIAGRO, 2012; Sivakumar et al., 2011). This index uses precipitation and ET as inputs. This index uses a relation between precipitation and ET:

$$
\mathrm{ADI}=\sum \mathrm{DI} /(3 n \mathrm{~N})
$$

where DI is determined based on the relationship between precipitation and ET, $n$ is the number of time periods, and $N$ is the number of periods with less than $10 \mathrm{~mm}$ of precipitation. The full ADI calculation is provided in Sivakumar et al. (2011). Whereas the ADI does use precipitation and ET, the relationship used in the DI calculation is somewhat subjective. Using the precipitation to ET relationship is a valid method for monitoring drought; however, the calculation should be based on a physical relationship. In addition, there is limited information available in the literature regarding the establishment or verification of the ADI.

\section{Relative Water Deficit}

The Relative Water Deficit (RWD) uses the ratio of actual ET to PET (Sivakumar et al., 2011) as:

$$
\mathrm{RWD}=\left(1-\frac{\mathrm{AET}}{\mathrm{PET}}\right) 100
$$

Using the ratio of actual to PET is an accurate measure of water stress. In RWD, if ET is occurring at the potential rate, the RWD is equal to zero, which indicates no stress. The RWD represents the diminished ET as a percentage that allows for comparisons across differing regions and time scales. In addition, the RWD can be calculated for any time scale. The main disadvantage to the RWD is that, whereas using actual ET can provide a good indication of water stress, it can be difficult to obtain. This can create problems when attempting to calculate the RWD for multiple sites or over a large geographical area. In many cases, a region will have varying crops in production. Using only one crop may not provide an accurate representation of multiple crops within the region.

Based on the literature review, it is concluded that the SPEI is the best method for agricultural drought monitoring as it uses both precipitation and $\mathrm{ET}_{\mathrm{o}}$ as inputs and is relatively simple to use. However, because of a large variability in water requirements of different crops grown in a region, using $\mathrm{ET}_{\mathrm{o}}$ for calculating SPEI alone may not be sufficient. Because crop ET is available for the Texas High Plains through the Texas High Plains ET (TXHPET) network, it would be advantageous to calculate a drought index using crop ET to derive crop-specific drought indices that could provide options for utilizing the most appropriate index or a crop-weighted SPEI. Therefore, in this study, the SPEI was revised by replacing reference ET with potential crop ET to enhance representation of actual agricultural water demand and be applicable to the Texas High Plains. 


\section{MATERIALS AND METHODS}

\section{Study Area}

The Texas High Plains is a significant portion of the Ogallala Aquifer region (Figure 1). Agriculture is a large portion of the land use and irrigated land accounts for the majority of agricultural production. Irrigation in this region uses about $89 \%$ of the total freshwater consumed, in contrast with about $60 \%$ for the state of Texas (Marek et al., 2010). The Texas High Plains is a major corn and cotton producing region in Texas. The vast majority of irrigation water is withdrawn from the underlying Ogallala Aquifer. Under modern climate and geologic circumstances, the Ogallala Aquifer in the region receives little to no recharge, and is essentially being mined. Consequently, conservation is an integral part of regional water plans (Marek et al., 2009). The northern and southern parts of the Texas High Plains are similar in size; however, the northern Texas High Plains has about 1.1 million ha under irrigation while the southern Texas High Plains has about 760,000 ha under irrigation (Colaizzi et al., 2008). In both northern and southern regions, irrigated crop yields are at least double neighboring dryland yields.
In the northern Texas High Plains, approximately $55 \%$ of cropland is irrigated and uses about $1.76 \mathrm{Gm}^{3}$ (1.43 million ac-ft) of water per year for irrigation (Marek et al., 2009). Irrigated winter wheat, corn, cotton, and grain sorghum are the predominant crops, comprising $30,26,23$, and $10 \%$ of the total irrigated area respectively (Colaizzi et al., 2008). Corn is a high water use crop requiring about $835 \mathrm{~mm}$ of ET from planting to maturity in the Texas High Plains (New and Dusek, 2005). Because of inadequate precipitation for corn production, an annual average of over $480 \mathrm{~mm}$ (19 in.) of irrigation is required in this region (Marek et al., 2009). Therefore, nearly all of the corn produced in this region is irrigated. Currently forage crops and silage feedstock are minor crops in the region; however, there has been major expansion in regional dairy production (Guerrero et al., 2012) and forages may soon become major irrigated crops.

In the southern Texas High Plains, cotton is the predominant crop comprising $65 \%$ of the total irrigated area (Colaizzi et al., 2008). The popularity of cotton in this area is a reflection of the water resource limitations where the saturated thickness of the Ogallala Aquifer decreases near the southern boundary. Cotton requires less irrigation water than the other predominant summer crops (Marek et al.,

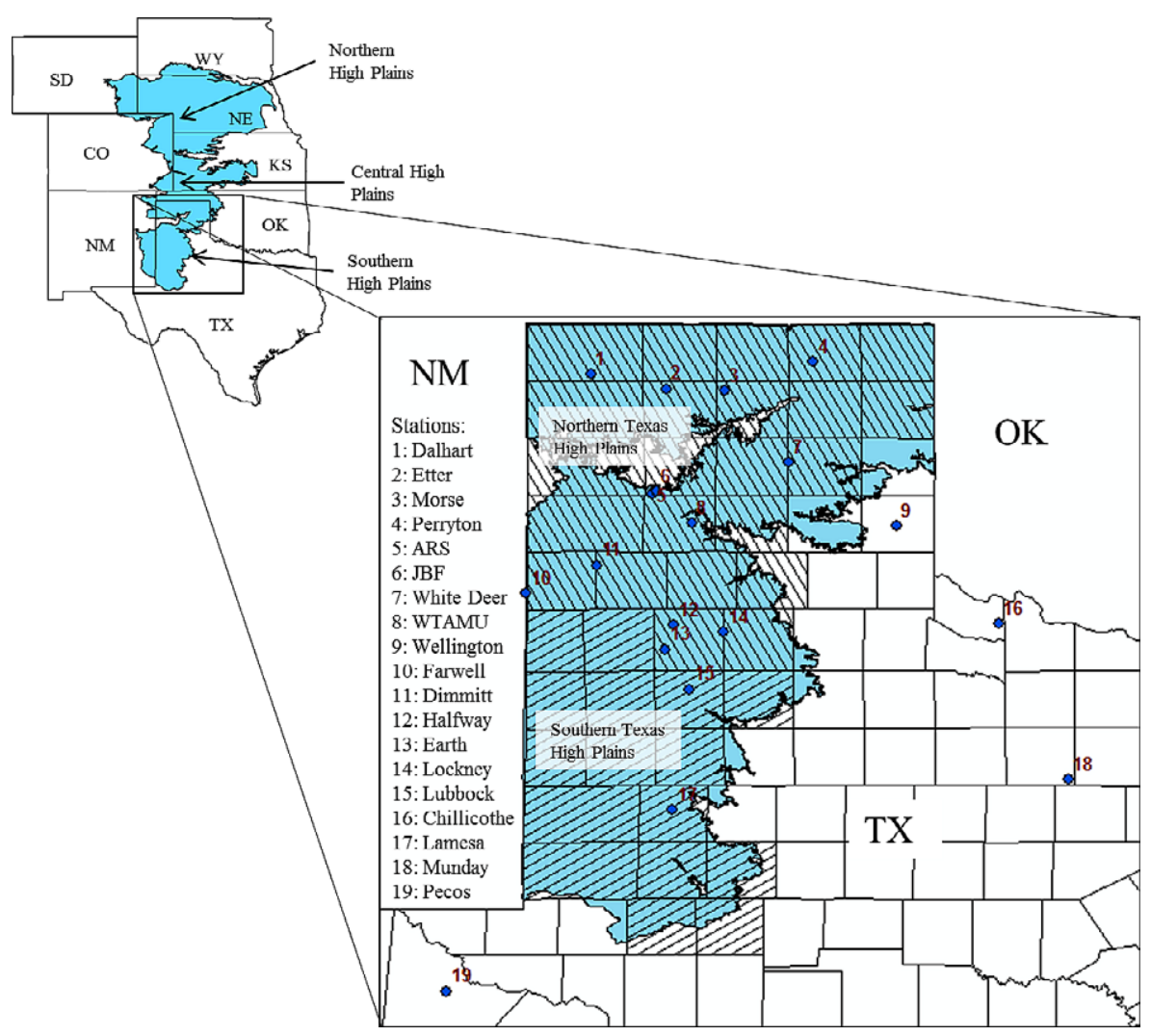

FIGURE 1. Locations of 19 Texas High Plains Evapotranspiration Weather Stations in the Texas High Plains. 
2009). Peanuts (Arachi hypogaea L.) are the second most grown crop in the southern region with about 9\% of total irrigated area (Colaizzi et al., 2008). Winter wheat and grain sorghum account for $7 \%$ of the irrigated area each, with corn only accounting for $3 \%$.

Because of the economic importance and large amount of water used for irrigated agriculture in the Texas High Plains, it is beneficial to understand the effects of climatic conditions on agricultural water use. As drought conditions develop, the irrigation water demand will increase. Therefore, monitoring drought conditions may provide valuable information for producers and groundwater districts to manage irrigated agriculture and rapidly declining groundwater storage in the Ogallala Aquifer region.

\section{Database Development}

Calculation of the SPEI was done using the precipitation and crop-specific PET data from the TXHPET network. The TXHPET network database contains data from 19 agro-meteorological weather stations throughout the Texas High Plains (see Figure 1). These weather stations are designed and installed with the purpose of collecting weather measurements for calculating PET for major crops within the region.

The TXHPET network records weather parameters at six-second intervals that are averaged or summed for hourly intervals. Measured weather parameters include precipitation, wind speed, air temperature, relative humidity, and solar radiation. These hourly measurements are used to calculate grass and alfalfa reference $\mathrm{ET}\left(\mathrm{ET}_{\mathrm{os}}\right.$ and $\mathrm{ET}_{\mathrm{rs}}$, respectively) using the 2005 ASCE Standardized Reference ET Equation (Allen et al., 2005), which are then summed to provide daily values. Prior to distribution to the public and end-users, the data undergo a quality control assessment to find and correct errors or missing data. This quality control procedure involves ensuring each measurement falls within realistic upper and lower limits as well as cumulative comparisons for weather stations within close proximity. Even though data undergo the TXHPET quality control, each dataset is additionally visually inspected for incorrect or missing data. Missing values were omitted rather than estimated from measurements of nearby stations.

Potential ET for major crops in the region was calculated by the TXHPET network using crop coefficients and $\mathrm{ET}_{\mathrm{os}}$. The crop coefficients correspond to the fraction (sometimes greater than 1) of reference ET used by a particular crop at a particular growth stage. Crop coefficients have been developed locally for six of the major crops commonly grown in the region (Howell et al., 2006). The precipitation and crop-specific PET values provide the necessary data to calculate SPEI. Here afterwards, potential crop ET is referred to as crop ET or $\mathrm{ET}_{\mathrm{c}}$.

The data obtained from the TXHPET network consist of precipitation and $\mathrm{ET}_{\mathrm{c}}$ for each crop between planting and harvesting dates. The six major crops in the Texas High Plains for which $\mathrm{ET}_{\mathrm{c}}$ values were reported are corn, cotton, soybean, sorghum, peanut, and winter wheat. The TXHPET network calculates and reports $\mathrm{ET}_{\mathrm{c}}$ for short season and long season varieties of each crop. In this study, $\mathrm{ET}_{\mathrm{c}}$ data for the long season variety were selected for calculating the crop-specific drought indices as they were the predominant varieties grown in the Texas High Plains. These varieties also were used in the calculation of county-wide irrigation demand projections for the regional water plan (Marek et al., 2009). Table 2 presents the planting dates and "crop end" date for the major crops considered in the drought index calculations. The growing season for all summer crops ended on October 31 for the purpose of SPEI calculation. For winter wheat, the crop ending date was taken as June 31.

For calculation of crop-specific SPEI at a monthly time-step, daily precipitation and $\mathrm{ET}_{\mathrm{c}}$ were summed to yield monthly values. If a particular month was flagged for missing daily data, the entire month was removed. This ensured that each month used would be a complete month of data and provide more accurate results. The monthly time step was chosen to provide a length that would help account for the variability in both precipitation and $\mathrm{ET}_{\mathrm{c}}$, yet was short enough to be useful for agricultural applications.

Using the precipitation and $\mathrm{ET}_{\mathrm{c}}$ values from the TXHPET network database, the $D_{i}$ values (Equation 3) were calculated. $\mathrm{ET}_{\text {os }}$ is calculated year-round, therefore the $D_{i}$ values were calculated for all months for $\mathrm{ET}_{\mathrm{os}}$. For the crop-specific $D_{i}$ values, the months outside of the growing season were set to zero. This was done because there was no $\mathrm{ET}_{\mathrm{c}}$ outside of the growing season, thus the $D_{i}$ values would all be positive and indicate an excess of water when in reality, that may not have been the case. Although some precipitation received outside of the growing season is

TABLE 2. Planting Dates for Major Crops in the Texas

High Plains Used by the TXHPET Network for Estimating Crop ET during Their Growing Season.

\begin{tabular}{llc}
\hline Crop & Planting Date & Crop Ending Date \\
\hline Corn & April 15 15 & October 31 \\
Cotton & May 15 & October 31 \\
Peanuts & May 1 & October 31 \\
Sorghum & May 15 & October 31 \\
Soybean & June 1 & October 31 \\
Winter wheat & September 10 & June 31 \\
\hline
\end{tabular}

Note: TXHPET, Texas High Plains Evapotranspiration; ET, evapotranspiration. 
stored in the soil profile, most of that water is usually evaporated (Jones and Popham, 1997). In the Texas High Plains, the distribution of precipitation indicates that most of the annual precipitation falls during the summer cropping season and little occurs in the winter months. Under irrigated conditions, water is applied shortly after planting, thus alleviating any drought conditions that may have developed. This is why the $D_{i}$ values outside of the growing season were set to zero, because those conditions will not have significant bearing on the soil conditions in the growing season. In addition, $\sim 50 \%$ of the annual $\mathrm{ET}_{\mathrm{os}}$ occurs outside of the summer growing season and could indicate drought conditions even though no crop is planted. This can lead to erroneous drought condition numerics. In irrigated agriculture, the soil water conditions are typically controlled on short intervals so the precipitation and $\mathrm{ET}_{\mathrm{c}}$ for the previous month should have little effect on the soil water for the current month. Hence, the cumulative effect of drought was not taken into account.

To develop the SPEI values, the crop specific $D_{i}$ values were calculated and standardized. The standardization was performed according to the procedure outlined in Vicente-Serrano et al. (2010). This involved using the log-logistic distribution with the parameters estimated using PWMs. According to a study by Guttman (1999), using different probability distributions can produce different results; consequently, the same three-parameter log-logistic probability distribution as Vicente-Serrano et al. (2010) was used to ensure consistency in the calculated values. The complete procedure for SPEI calculation can be found in Vicente-Serrano et al. (2010). After calculation, trends and magnitudes of the cropspecific SPEI were compared and discussed.

\section{RESULTS AND DISCUSSION}

\section{Database Development}

Climatic data for this study were obtained from the TXHPET network managed by the Texas A\&M AgriLife Research and Extension Service. In this network, weather data are collected over a grass reference crop and specifically developed for providing daily $\mathrm{ET}_{\mathrm{c}}$ to producers in the Texas High Plains. Because the region has limited topographic relief and regional differences in weather are minimal, a single station (Bushland, Texas) was selected for the period of 1997-2010. The data were inspected for missing or incorrect data, which were removed if found. The number of SPEI data points removed was negligible.

\section{Monthly Average Precipitation}

Figure 2 illustrates the monthly average precipitation recorded by 12 of the TXHPET network weather stations in the study area for the study period (19972010). The average monthly precipitation for all 12 weather stations indicated that peak monthly precipitation generally occurs in June followed by August and October. Precipitation in June usually provides water for planting and establishment of summer crops. Precipitation that occurs in August usually reduces a part of the crop water demand, potentially during the reproductive growth stage for summer crops where water stress can reduce yields; however, any delay in the occurrence of precipitation by two or more weeks is expected to increase the irrigation demand significantly, which can adversely affect crop yield, particularly for cotton. This is because, though grown as an annual crop (terminated by late season freezing temperatures), biologically cotton is a perennial crop and tends to use its energy to grow the plant instead of developing bolls when more water is available in the root zone.

Typically irrigated summer crops in the Texas High Plains receive the last irrigation application during the second or third week of August. Precipitation during the month of October does not directly contribute to summer crops; although it provides soil water for planting and plant growth in the early stages of winter wheat. Comparison of monthly average precipitation from individual stations indicated that weather stations located in the eastern portion of the Texas High Plains (White Deer, Chillicothe, and Perryton) recorded greater than average monthly precipitation for the Texas High Plains; conversely,

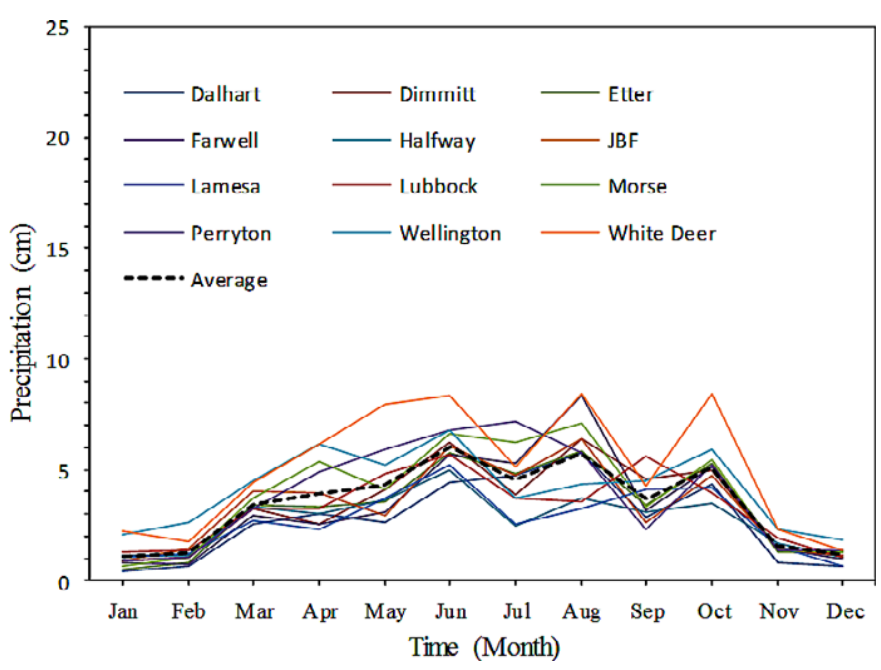

FIGURE 2. Monthly Average Precipitation Recorded by the 12 Texas High Plains Evapotranspiration Network Weather Stations in the Texas High Plains. 
monthly precipitation values from stations along a single longitudinal transect (e.g., $102^{\circ} \mathrm{N}$ ) were similar or slightly below the monthly average precipitation for the entire region. This is because precipitation in the Texas High Plains does not vary in the North-toSouth (N-S) direction and has a positive gradient in the West-to-East (W-E) direction (Chebrolu, 2006).

\section{Monthly Average Grass Reference ET}

Figure 3 illustrates the monthly average $\mathrm{ET}_{\text {os }}$ for 12 TXHPET network weather stations in the study area for the study period (1997-2010). Comparison of the $\mathrm{ET}_{\mathrm{os}}$ curves among the 12 weather stations indicated that $\mathrm{ET}_{\mathrm{os}}$ gradually increases in the N-S direction. Larger values can be observed during the summer growing season where limited precipitation is supplemented by irrigation for maintaining profitable yield levels. Relatively greater $\mathrm{ET}_{\mathrm{os}}$ for stations in the southern half of the Texas High Plains, when compared with the northern half, is mainly due to their relatively lower latitude positions and elevations. Regions at lower latitudes receive more solar energy and record higher air temperatures that contribute to higher reference ET and crop water demand. Comparison of monthly average precipitation and $\mathrm{ET}_{\mathrm{os}}$ for the Texas High Plains (Figures 2 and 3) indicated that precipitation meets approximately one-fourth of the crop water demand during the summer growing season and the remaining has to come from stored soil water and irrigation applications.

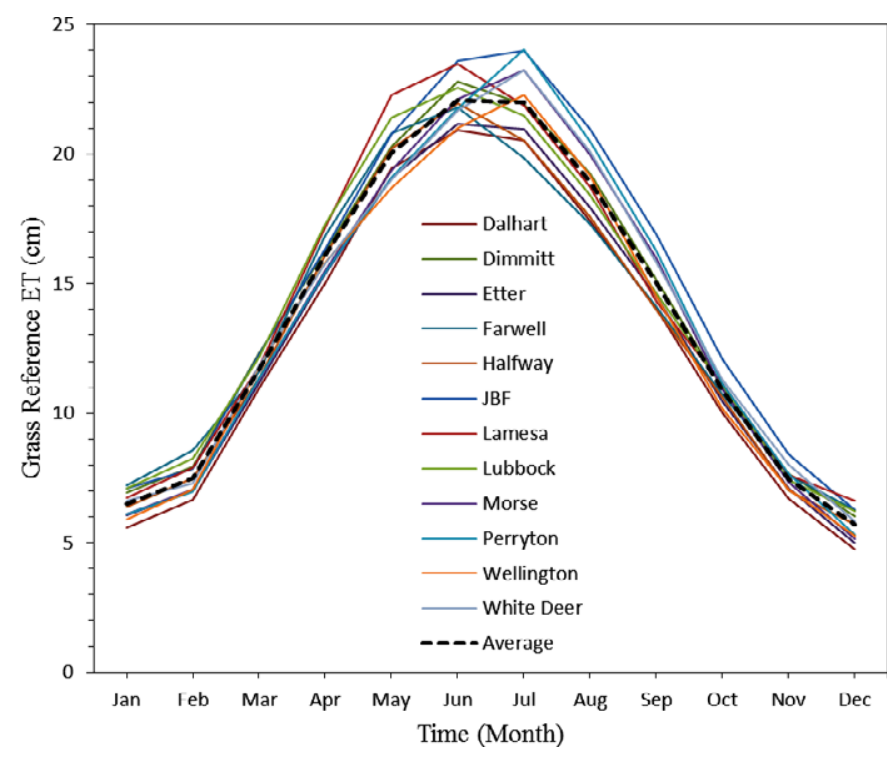

FIGURE 3. Monthly Average Grass Reference Evapotranspiration (ET) Recorded by the 12 Texas High Plains Evapotranspiration Network Weather Stations in the Texas High Plains.

\section{SPEI Time Series}

Figure 4 illustrates the SPEI time series at a monthly time-step for grass (reference crop), corn, sorghum, peanut, cotton, soybean, and winter-wheat, respectively, for the Bushland, Texas location. Precipitation, $\mathrm{ET}_{\mathrm{os}}$, and $\mathrm{ET}_{\mathrm{c}}$ from the Bushland TXHPET network weather station were used for calculating the crop-specific SPEI.

In the crop-SPEI time series, positive values indicate wetter conditions and negative values represent drought conditions requiring irrigation during the cropping season. The greater the negative SPEI values, the greater the irrigation demand in that month. Similar trends were found in all crop-specific SPEI time series, although at a different magnitude as expected. For example, negative values $(-0.8$ to -2$)$ of corn-SPEI, indicating a shortage of precipitation to meet the crop water demand, occurred in the month of July and positive SPEI values $(+1$ to +1.9$)$ were found in the April months, indicating excess soil water at the time of planting. These trends were found to be similar for sorghum. These trends were also found with other major summer crops in the Texas High Plains, such as soybean and cotton, however, at relatively smaller magnitude. This is attributable to the fact that SPEI uses the difference between precipitation and crop ET for calculating the index, and $\mathrm{ET}_{\mathrm{c}}$ for corn and sorghum at any given month is relatively higher than that for other summer crops (soybean and cotton) in the Texas High Plains.

When comparing the crop-specific SPEIs to the reference crop SPEI (Vicente-Serrano et al., 2010), it is clear that there are large differences in magnitudes. There are instances where the reference SPEI indicated near neutral conditions while crop-specific SPEI indicated drought conditions. One example is August 1997. The reference SPEI value is 0.12; indicating neutral conditions, whereas the crop-specific SPEIs ranged from -1.10 to -1.50 . This happens when a crop coefficient greater than one is used, which indicates that the crop uses more water than the grass reference crop. This condition exists in various growth stages of most crops grown on the Texas High Plains. Another interesting fact is that the magnitudes vary between the different crop SPEIs. For reference SPEI, the values ranged from -2.17 to +2.85 for the study period whereas corn SPEI ranged from -2.03 to +6.89 . This illustrates that the use of $\mathrm{ET}_{\mathrm{os}}$ in the drought index does not accurately reflect the crop-specific water demand. In the earlier growth stages of the crops, the plants use much less water than the grass reference crop. This creates situations where the reference SPEI can indicate drought conditions when in actuality, wet conditions can occur. 


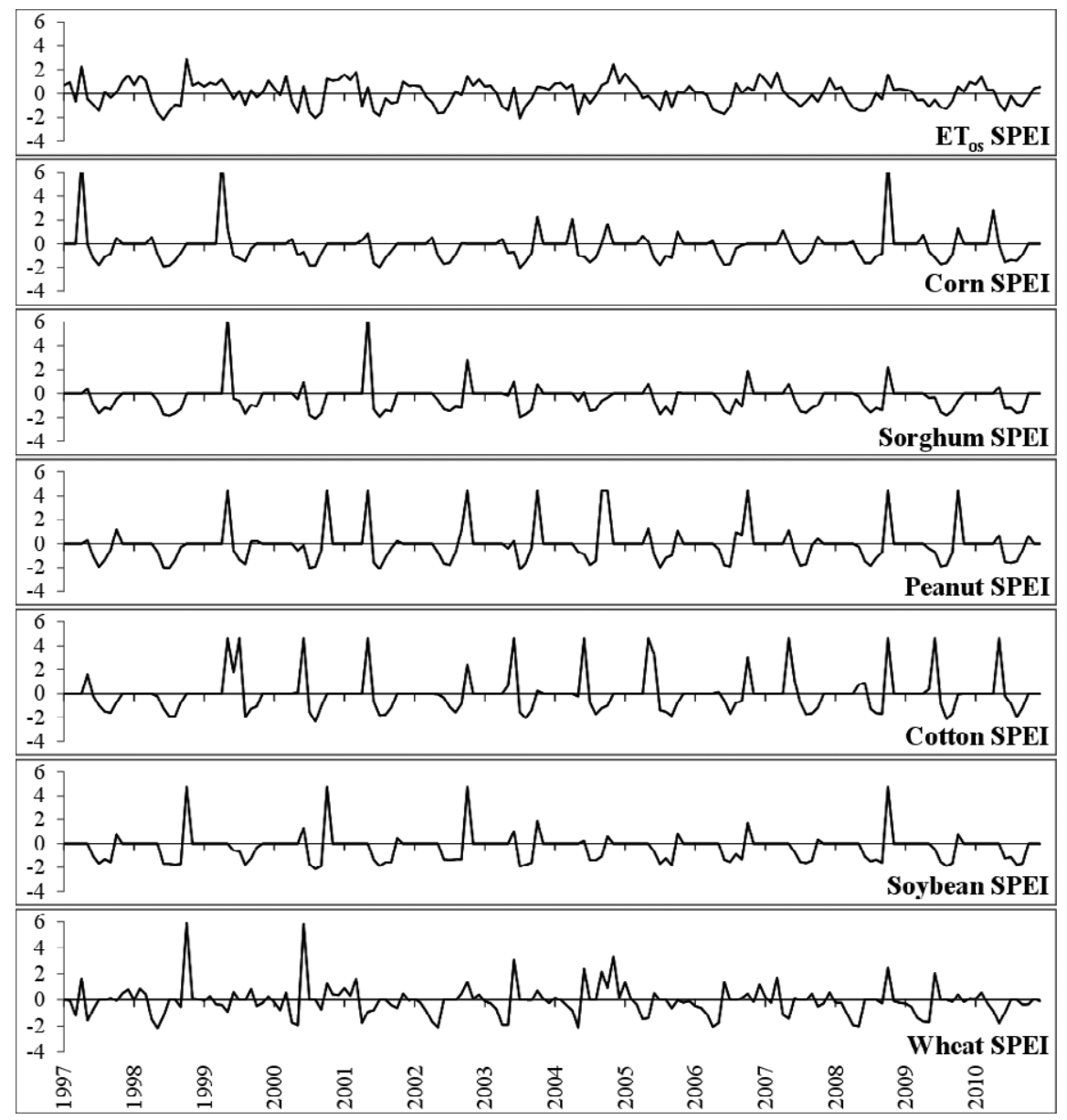

FIGURE 4. Time-Series Graphs of Standardized Precipitation-Evapotranspiration Index (SPEI) and Crop-Specific SPEI for Bushland, Texas.

With the use of crop-specific SPEI, it is possible that one crop may be under drought conditions while another crop could be experiencing wet conditions in the same month. One example of this situation is July 1999 where reference SPEI is +0.21 , corn SPEI is -1.23 , and cotton SPEI is +4.57 indicating near neutral conditions, dry conditions, and very wet conditions for different crops in the same month. This leads to the conclusion that reference ET should be replaced with crop ET if SPEI were to be used in agricultural drought monitoring in semiarid regions, where limited rainfall is supplemented with irrigation for sustainable crop production. Furthermore, crops have different growing seasons and growthstage dependent crop-coefficient curves; therefore, timing and magnitude of drought conditions may vary among the crops (i.e., cotton is typically planted later than most of the other summer crops in the Texas High Plains). In addition, the seasonal ET for cotton is typically lower and needs water stress conditions in August to produce cotton bolls while inhibiting biomass production. This requires crop-specific drought indices for monitoring agricultural drought.
This is very important in the Texas High Plains where groundwater management districts sometimes revise their allowable pumping rates for irrigation based on the drought conditions. Trends in the timing and magnitude of SPEI values for winter wheat varied from that of summer crops for the apparent reason that its growing season was different from that of summer crops. Having a drought index that is based on the crop grown in a given region can better indicate drought conditions in that region.

Crop-specific SPEI seems to have the potential to provide simpler, more accurate drought monitoring in semiarid agricultural regions. A crop-specific drought index can allow for region-specific drought monitoring based on the crops being produced, which can provide necessary information for managing water resources more effectively. This would include potentially estimating irrigation demand; however, it is based on the assumption that irrigated crops are managed by meeting $100 \%$ of the crop water demand. It may not always be true as producers in the Texas High Plains, and in other parts of the world, are moving toward deficit irrigation (Hernandez et al., 2013) due to either water use 
restrictions or unavailability of adequate water resources for full irrigation. Recent developments in satellite-based thermal ET remote sensing approaches may offer an opportunity to further improve SPEI for agricultural monitoring purposes at a regional scale as they provide actual ET estimates at high spatial resolutions (Gowda et al., 2008, 2009).

\section{CONCLUSIONS}

A thorough literature review indicated that the SPEI is found to be an appropriate drought index for monitoring agricultural drought in arid and semiarid regions such as the Texas High Plains; however, potential crop ET should be used in place of reference ET to calculate the SPEI for better monitoring of agricultural drought and to manage groundwater resources efficiently. Trends in the timing and magnitude of monthly average precipitation and $\mathrm{ET}_{\mathrm{os}}$ clearly indicated that irrigation is crucial to meeting crop water demands and attaining profitable yields. A set of crop-specific SPEI values were calculated and compared using precipitation and crop-specific ET from the TXHPET network in the Texas High Plains. Following the SPEI procedure to obtain reference crop and crop-specific SPEI was relatively simple. The trends and magnitude of the crop-specific SPEIs clearly agreed with the growing season for summer crops in the region and have the potential to be used for developing simple tools to estimate regional irrigation demand.

\section{ACKNOWLEDGMENT}

We gratefully acknowledge support from the USDA-ARS Ogallala Aquifer Program, a consortium between USDA-Agricultural Research Service, Kansas State University, Texas A\&M AgriLife Research, Texas A\&M AgriLife Extension Service, Texas Tech University, and West Texas A\&M University.

\section{LITERATURE CITED}

Allen, R.G., I.A. Walter, R.L. Elliott, T.A. Howell, D. Itenfisu, M.E. Jensen, and R.L. Snyder, 2005. The ASCE Standardized Reference Evapotranspiration Equation. American Society of Civil Engineers, Reston, Virginia.

Alley, W.M., 1984. The Palmer Drought Severity Index: Limitations and Assumptions. Journal of Climate and Applied Meteorology 23:1100-1109.

Baumhardt, R.L., S.A. Mauget, P.H. Gowda, and D.K. Brauer, 2014. Modeling Cotton Lint Yield Response to Irrigation Management as Influenced by El Nino-Southern Oscillation. Agronomy Journal 106:1-10.
Blumenstock, Jr., G., 1942. Drought in the Unites States Analyzed by Means of the Theory of Probability. USDA Tech Bull. 819, $63 \mathrm{pp}$.

Chebrolu, K.K., 2006. Precipitation Patterns along a N-S Transect in the Ogallala Aquifer Region. M.S. Thesis, West Texas A\&M University, Canyon, Texas. Print.

CIIAGRO, 2012. Integrated Center of Agrometeorological Information. http://www.infoseca.sp.gov.br/, accessed August 2012.

Colaizzi, P.D., P.H. Gowda, T.H. Marek, and D.O. Porter, 2008. Irrigation in the Texas High Plains: A Brief History and Potential Reductions in Demand. Irrigation and Drainage 58(3): 257-274, doi: 10.1002/ird.418.

Dracup, J.A., K.S. Lee, and E.G. Paulson, Jr., 1980. On the Definition of Droughts. Water Resources Research 16:297-302.

Gowda, P.H., J.L. Chàvez, P.D. Colaizzi, S.R. Evett, T.A. Howell, and J.A. Tolk, 2008. ET Mapping for Agricultural Water Management: Present Status and Challenges. Irrigation Science 26(3): 223-237, doi: 10.1007/s00271-007-0088-6.

Gowda, P.H., G.B. Senay, T.H. Howell, and T.H. Marek, 2009. Lysimetric Evaluation of Simplified Energy Balance Approach in the Texas High Plains. Applied Engineering in Agriculture 25(5): 665-669.

Guerrero, B., S. Amosson, and E. Jordan, 2012. The Impact of the Dairy Industry in the Southern Ogallala Region. B-6252. Texas A\&M AgriLife Extension Service, College Station, Texas.

Guttman, N.B., 1999. Accepting the Standardized Precipitation Index: A Calculation Algorithm. Journal of the American Water Resources Association 35:311-322.

Hayes, M.J., 2006. Drought Indices. Van Nostrand's Scientific Encyclopedia. John Wiley \& Sons, Inc.

Heim, R., 2002. A Review of Twentieth-Century Drought Indices Used in the United States. Bulletin of the American Meteorological Society 83:1149-1165.

Hernandez, J.E., P.H. Gowda, T.A. Howell, T.H. Marek, and W. Ha, 2013. Groundwater Levels in Northern High Plains: Baseline for Existing Agricultural Management Practices. Texas Water Journal 4(1):22-34.

Howell, T.A., S.R. Evett, J.A. Tolk, K.S. Copeland, D.A. Dusek, and P.D. Colaizzi, 2006. Crop Coefficients Developed at Bushland, Texas for Corn, Wheat, Sorghum, Soybean, Cotton, and Alfalfa. Proceedings of the World Environmental and Water Resources Congress, May 21-24, EWRI, ASCE (CD-ROM), Omaha, Nebraska.

Jones, O.R. and T.W. Popham, 1997. Cropping and Tillage Systems for Dryland Grain Production in the Southern High Plains. Agronomy Journal 89(2):222-232.

Karl, T.R., 1986. The Sensitivity of the Palmer Drought Severity Index and Palmer's Z-Index to Their Calibration Coefficients Including Potential Evapotranspiration. Journal of Climate and Applied Meteorology 25:77-86.

Kincer, J.B., 1919. The Seasonal Distribution of Precipitation and Its Frequency and Intensity in the Unites States. Monthly Weather Review 47:624-631.

Kogan, F.N., 1995. Droughts of the Late 1980s in the United States as Derived from NOAA Polar-Orbiting Satellite Data. Bulletin of the American Meteorological Society 76:655-668.

Marcovitch, S., 1930. The Measure of Droughtiness. Monthly Weather Review 58:113.

Marek, T., S. Amosson, F. Bretz, B. Guerrero, and R. Kotara, 2009. 2011 Panhandle Regional Water Plan Task 2 Report: Agricultural Water Demand Projections. Technical Report for the Texas Water Development Board (Water Planning Division) and Region A Panhandle Regional Planning Group through Freese and Nichols, Inc. Texas A\&M AgriLife, Amarillo, Texas. AREC 09-21, 83 pp.

Marek, T.H., D.O. Porter, P. Gowda, T.A. Howell, and J.E. Moorhead, 2010. Assessment of Texas Evapotranspiration (ET) Net- 
works. Technical Report for Contract \#0903580904 to the Texas Water Development Board, Austin, Texas. Texas AgriLife Research, Amarillo, Texas. AREC publication 201011-12, 379 pp.

McGuire, J.K. and W.C. Palmer, 1957. The 1957 Drought in the Eastern United States. Monthly Weather Review 85:305-314.

McKee, T.B., N.J. Doesken, and J. Kleist, 1993. The Relationship of Drought Frequency and Duration to Time Scales. Eighth Conference on Applied Climatology, January 17-22. American Meteorological Society, Anaheim, California, pp. 179-184.

Mishra, A.K. and V.P. Singh, 2010. A Review of Drought Concepts. Journal of Hydrology 391:202-216.

Munger, T.T., 1916. Graphic Method of Representing and Comparing Drought Intensities. Monthly Weather Review 44:642643.

Narasimhan, B. and R. Srinivasan, 2005. Development and Evaluation of Soil Moisture Deficit Index (SMDI) and Evapotranspiration Deficit Index (ETDI) for Agricultural Drought Monitoring. Agricultural and Forest Meteorology 133:69-88.

NDMC (National Drought Mitigation Center), 2013. U.S. Drought Monitor. http://drought.unl.edu/MonitoringTools/USDroughtMoni tor.aspx, accessed March 2013.

New, L. and D. Dusek, 2005. Ogallala Aquifer 2004 Annual Report - Crop Irrigation and Production. Amarillo, Texas: Texas Coop. Ext. Serv.

Palmer, W.C., 1965. Meteorological Drought. U.S. Weather Bureau. Research Paper No. 45, 58 pp.

Palmer, W.C., 1968. Keeping Track of Crop Moisture Conditions, Nationwide: The New Crop Moisture Index. Weatherwise 21(4):156161.

Peters, A.J., E.A. Walter-Shea, L. Ji, A. Vina, M. Hayes, and M.D. Svoboda, 2002. Drought Monitoring with NDVI-Based Standardized Vegetation Index. Photogrammetric Engineering \& Remote Sensing 68(1):71-75.

Quiring, S.M., 2009. Monitoring Drought: An Evaluation of Meteorological Drought Indices. Geography Compass 3:64-88, doi: 10. 1111/j.1749-8198.2008.00207.x.

Shafer, B.A. and L.E. Dezman, 1982. Development of a Surface Water Supply Index (SWSI) to Assess the Severity of Drought Conditions in Snowpack Runoff Areas. Proceedings of the Western Snow Conference 50:164-175.

Sivakumar, M.V.K., R.P. Motha, D.A. Wilhite, and D.A. Wood (Editors), 2011. Agricultural Drought Indices. Proceedings of the WMO/UNISDR Expert Group Meeting on Agricultural Drought Indices, June 2-4, 2010, Murcia, Spain. World Meteorological Organization, Geneva, Switzerland. AGM-11, WMO/TD No. 1572; WAOB-2011, 219 pp.

Thornthwaite, C.W., 1948. An Approach toward a Rational Classification of Climate. Geographical Review 30:55-94.

Tsakiris, G. and H. Vangelis, 2005. Establishing a Drought Index Incorporating Evapotranspiration. European Water 9(10):3-11.

UNEP, 1992. World Atlas of Desertification. Edward Arnold, London, United Kingdom.

Vicente-Serrano, S.M., S. Beguería, and J.I. López-Moreno, 2010. A Multi-Scalar Drought Index Sensitive to Global Warming: The Standardized Precipitation Evapotranspiration Index - SPEI Journal of Climate 23(7):1696-1718, doi: 10.1175/2009JCLI2909.1.

Wilhite, D.A. and M.H. Glantz, 1985. Understanding the Drought Phenomenon: The Role of Definitions. Water International 10:111-120. 